\title{
Study on Profile of Benign Breast Diseases at VIMS, Pawapuri
}

\author{
Bal Mukund Prasad', Prabhat Kumar Lal ${ }^{2}$, Ashok Kumar Jha ${ }^{3}$, Rajesh Narayan ${ }^{4}$ \\ ${ }^{1}$ Senior Resident, Department of Surgery, Vardhman Institute of Medical Sciences, Pawapuri, ${ }^{2}$ Assistant Professor, Department of Community Medicine, Darbhanga \\ Medical College, Darbhanga, ${ }^{3}$ Associate Professor, Department of Surgery, Vardhman Institute of Medical Sciences, Pawapuri, ${ }^{4}$ Assistant Professor, Department of \\ Surgery, Vardhman Institute of Medical Sciences, Pawapuri
}

\section{Abstract}

Background: Benign breast diseases are common cause of breast related illnesses. Proper assessment of cases is helpful in diagnosis and avoids unnecessary complications. Subjects and Methods: The present hospital based study was conducted upon 48 cases of benign breast illnesses to assess the clinico-aetiological profile. Background details of patients, detailed history and findings of clinical examination were recorded. Results: Most of the patients belonged to the age group of 21-30 years. Breast lump only was the most common presentation (62.5\%), fibroadenoma was the most common cause (54.2\%) and right side was most commonly involved (37.5\%). Conclusion: Fibroadenoma is the most common cause of benign breast disease in this area.

Keywords: Benign, Breast disease.

Corresponding Author: Dr. Prabhat Kumar Lal, Department of Community Medicine, Darbhanga Medical College, Darbhanga, Bihar, PIN846003 .

Received: January 2019

Accepted: February 2019

\section{Introduction}

Benign breast diseases are a group of non-malignant condition of breast which is common in females. It affects up to $30 \%$ of females who need to seek treatment for this condition. $^{[1]}$ It is caused by heterogenous conditions including developmental abnormality, epithelial and stromal proliferation, inflammatory lesions and neoplasm. It is thought that Aberration in Normal Development and Involution (ANDI) is responsible for this condition which is the result of derangement of hormones and growth factors acting on the epithelial and stromal elements of breast. Infection to the breast may cause abscess formation. ${ }^{[2]}$

It causes physical symptoms in terms of pain and discomfort as well as psychological problems in terms of anxiety and fear of malignancy. Assessment of benign breast diseases involves triple assessment- clinical examination, imaging and histopathological assessment. ${ }^{[3]}$

Treatment involves careful diagnosis and conservative management of the condition. Surgery is needed in those not responding to conservative treatment or with a large tumour.

It is a common condition accounting to up to $85 \%$ of consultations due to breast conditions. ${ }^{[4]}$ Studies regarding this has not been done in this place.

\section{Aims \& objectives}

The present study was conducted to find the pattern and clinical features of benign breast diseases among female patients reporting to Surgery OPD of VIMS, Pawapuri.

\section{Subjects and Methods}

The present study was cross-sectional in nature conducted at the department of Surgery, VIMS, Pawapuri. Female patients reporting to the department with complaints related to breast were included. Those with apparent malignancy and those already diagnosed with one were excluded. A total of 48 cases reporting during the data collection period were studied.

Detailed clinical history and local and systemic examination of all the cases was done. Diagnosis was made according to clinical findings and relevant investigations which included FNAC and ultrasound imaging. Conservative treatment was first tried and surgery was done when needed. Patients having benign breast diseases and inflammatory lesions were only included in this study.

Pretested proforma was used for data collection, Microsoft Excel for data entry and SPSS v 16.0 for data analysis. Data collection was done only after taking informed consent. Records were kept confidentially.

\section{Results}

\begin{tabular}{|l|l|l|l|}
\hline Table 1: Age distribution of the study subjects. \\
\hline Age group & Frequency & $\mathbf{\%}$ & $\mathbf{9 5 \%}$ CI \\
\hline$<20$ & 4 & 8.3 & $3.3-19.6$ \\
\hline $21-30$ & 21 & 43.8 & $30.7-57.7$ \\
\hline $31-40$ & 13 & 27.1 & $16.6-41$ \\
\hline $41-50$ & 7 & 14.6 & $7.2-27.2$ \\
\hline $51-60$ & 3 & 6.3 & $1.2-14$ \\
\hline
\end{tabular}


A total of 48 patients were included in the present study. [Table 1] shows the age distribution of study subjects. Most of the patients belonged to the age group of 21-30 years. Only $6.3 \%$ patients were above the age of 50 years.

[Table 2] shows the chief complaints of the patients. Most of the patients presented with breast lump only (62.5\%). $14.6 \%$ presented with lump and pain while $16.7 \%$ had pain only. $6.3 \%$ patients suffered from nipple discharge.

\begin{tabular}{|l|l|l|l|}
\hline Table 2: Presenting complaints of patients with breast lump. \\
\hline Presenting complaints & Frequency & \% & 95\% CI \\
\hline Breast lump only & 30 & 62.5 & $48.4-74.8$ \\
\hline Breast lump +pain & 7 & 14.6 & $7.2-27.2$ \\
\hline $\begin{array}{l}\text { Breast lump +nipple } \\
\text { discharge }\end{array}$ & 2 & 4.2 & $1.2-14$ \\
\hline Breast pain only & 8 & 16.7 & $8.7-29.6$ \\
\hline Nipple discharge only & 1 & 2.1 & $0.4-10.9$ \\
\hline
\end{tabular}

[Table 3] shows the diagnosis of breast lump. Fibroadenoma was present in $54.2 \%$ patients while $27.2 \%$ had fibroadenosis. $6.3 \%$ had breast abscess also.

\section{Table 3: Diagnosis of breast lump}

\begin{tabular}{|l|l|l|l|}
\hline Diagnosis & Frequency & $\mathbf{\%}$ & $\mathbf{9 5 \%}$ CI \\
\hline Fibroadenoma & 26 & 54.2 & $40.1-68.3 \%$ \\
\hline Fibroadenosis & 13 & 27.1 & $16.6-41$ \\
\hline Breast abscess & 3 & 6.3 & $1.2-14$ \\
\hline Mastitis & 3 & 6.3 & $0.4-10.9$ \\
\hline Duct ectasia & 2 & 4.2 & $0.4-10.9$ \\
\hline Galactocoele & 1 & 2.1 & $0.4-10.9$ \\
\hline
\end{tabular}

[Table 4] shows the side of breast involved. Right side was involved in $37.5 \%$, left side in $33.3 \%$ and $29.2 \%$ had involvement of both sides. Table-5 shows the details of breast quadrant involved. Upper outer quadrant was involved in about one-third of the cases $(62.5 \%)$.

\section{Table-4: Side of breast involved}

Table-4: Side of breast involved
\begin{tabular}{|l|l|l|l|}
\hline Side & Frequency & $\%$ & 95\% CI \\
\hline Right & 18 & 37.5 & $25.2-51.6$ \\
\hline Left & 16 & 33.3 & $21.7-47.5$ \\
\hline Both & 14 & 29.2 & $18.2-43.2$ \\
\hline
\end{tabular}

Table-5: Involvement of quadrant of breast

\begin{tabular}{|l|l|l|l|}
\hline $\begin{array}{l}\text { Quadrant of } \\
\text { breast involved }\end{array}$ & Frequency & $\mathbf{\%}$ & $\mathbf{9 5 \%}$ CI \\
\hline Upper Outer & 30 & 62.5 & $48.4-74.8$ \\
\hline Upper Inner & 5 & 10.4 & $4.5-22.2$ \\
\hline Lower Outer & 4 & 8.3 & $3.3-19.6$ \\
\hline Lower Inner & 2 & 4.2 & $1.2-14$ \\
\hline Central & 6 & 12.5 & $5.9-24.7$ \\
\hline
\end{tabular}

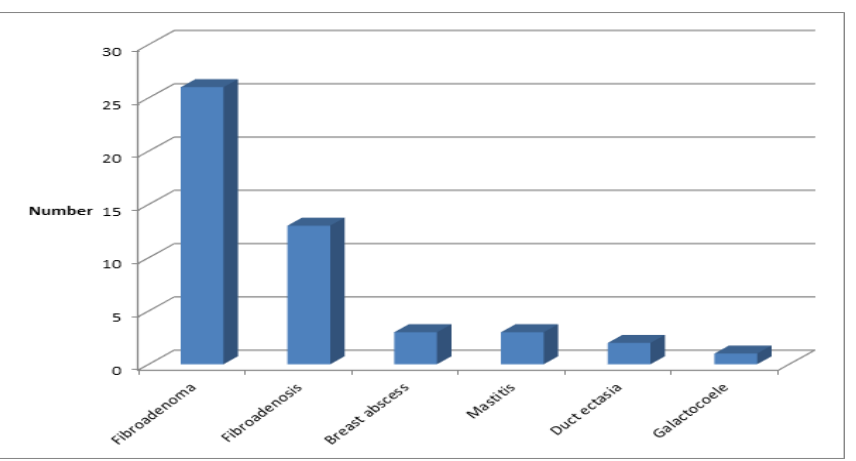

Chart-1 showing diagnosis in benign breast diseases

\section{Discussion}

A total of 48 patients of benign breast diseases were included. The most common age group in the present study was $21-30$ years $(43.8 \%) .6 .3 \%$ patients were above the age of 50 years. Hatim et al found that $43 \%$ patients were in the age group of 21-30 years while only $3.2 \%$ were above 50 years. ${ }^{[5]}$ Chauhan et al observed that benign breast disease was commonest 21-30 years age group (46.7\%) while Karki et al reported that $67 \%$ patients were in age group of $21-40$ years. ${ }^{[6,7]}$ Most commonly affected age group of benign breast disease was 21-30 yrs in the study done by Lakshmi et al also. ${ }^{[8]}$ In the study done by Kumar et al, fibroadenoma was more commonly seen in age group of 11-30 years constituting $74.3 \%$ of all cases followed by $18.1 \%$ cases in age group of 31-40 years. ${ }^{[9]}$

Most of the patients complained of only breast lump (62.5\%). $14.6 \%$ had lump and pain while $16.7 \%$ had pain only. Nipple discharge was seen in $6.3 \%$ patients. Hatim et al observed that $76.2 \%$ cases presented with painless lump while rest with painful lump. ${ }^{[5]}$ Karki et al found that the commonest presentation was pain (45\%), followed by lump $(26 \%) \cdot{ }^{[7]}$

The diagnosis was fibroadenoma in $54.2 \%$, fibroadenosis in $27.2 \%$ and breast abscess in $6.3 \%$. In the study done by Hatim et al, the commonest benign breast lesion was fibroadenoma $(77.62 \%)$, followed by fibrocystic disease (4.3\%) and gynaecomastia (4.3\%). Lakshmi et al noted that fibroadenoma was the most common benign breast disease $(52.85 \%)$, followed by fibrocystic disease (25.71\%), cystosarcoma phyllods, galactocele, traumatic fat necrosis, lipoma, ductal ectasia and tubular adenoma. ${ }^{[5]}$ Chauhan et al reported that $63.80 \%$ patients presented with breast lumps and fibroadenoma, accounted for $46.66 \%$ of the cases, which was the highest number of patients. ${ }^{[6]}$ Karki et al noted that fibroadenoma accounted for $46 \%$ cases. $^{[7]}$

Right side was involved in $37.5 \%$, left side in $33.3 \%$ and $29.2 \%$ had involvement of both sides. Upper outer quadrant was involved in about one-third of the cases $(62.5 \%)$ and upper inner in $10.4 \%$. Central quadrant was involved in $12.5 \%$ cases. Lump in the left breast was seen in $48 \%$ followed by right breast in $45 \%$ and bilateral fibroadenoma of breasts were seen in 7\% in the study done by Hatim et al. Most of the cases $(62 \%)$ were noted in upper outer quadrant. ${ }^{[5]}$ Lakshmi et al found that fibroadenoma occurred more on right breast $(57.35 \%)$ than left breast $45.9 \%$ and bilateral involvement was seen in one case $(2.70 \%)$. Fibrocystic diseases occurred more commonly in right breast (50\%) than left breast (33.35\%) and it was bilateral in $16.66 \% .{ }^{[8]}$ Kumar et al reported that $47.63 \%$ cases had right sided breast involvement while $39.73 \%$ had left breast involvement whereas bilateral involvement was seen in $12.63 \%$ patients. ${ }^{[9]}$ Chauhan et al found that the right breast was involved in $42.85 \%$ patients, and upper outer quadrant was most commonly involved $(59.04 \%) \cdot{ }^{[6]}$ Karki also found that left breast was affected in $44 \%$ of patients, right in $32 \%$ and $24 \%$ of patients had symptoms in both the breasts. ${ }^{[7]}$ It is seen that the presentation and aetiology of benign 
breast disease is similar to the trends in other areas. High degree of suspicion, proper diagnosis and management is essential in treatment of benign breast diseases.

\section{Conclusion}

It is seen that benign breast diseases are common cause of breast related morbidity in this area. Thorough investigation is helpful in correct diagnosis and proper treatment. Fibroadenoma is the most common cause and breast lump is the commonest complain.

\section{References}

1. Guray M, Sahin AA. Benign Breast Diseases: Classification, Diagnosis, and Management. Oncologist 2006; 11: 435-49.

2. Santen RJ, Mansel R. Benign Breast Disorders. N Engl J Med 2005; 353: $275-85$.

Copyright: (C) the author(s), 2019. It is an open-access article distributed under the terms of the Creative Commons Attribution License (CC BY 4.0), which permits authors to retain ownership of the copyright for their content, and allow anyone to download, reuse, reprint, modify, distribute and/or copy the content as long as the original authors and source are cited.

How to cite this article: Prasad BM, Lal PK, Jha AK, Narayan R. Study on Profile of Benign Breast Diseases at Vims, Pawapuri. Asian J. Med. Res. 2019;8(1):SG14-SG16.

DOI: dx.doi.org/10.21276/ajmr.2019.8.1.SG5

Source of Support: Nil, Conflict of Interest: None declared.
3. Srivatsava A, Dhar A. Benign Breast Disease: A neglected entity. Recent Advances in Surgery 2006; 10: 175-201.

4. Sayami P, Singh BM, Singh Y, et alRetrospective analysis of breast cancer casesand surgical treatment in a period of 10 years JNMA 2001; 40: 112-119.

5. Hatim KS, Laxmikant NS, Mulla T. Patterns and prevalence of benign breast disease in Western India. Int $\mathrm{J}$ Res Med Sci 2017;5:684-8.

6. Chauhan DS, Jain N. Profile of benign breast disease in Uttarakhand. JMSCR 2018; 06 (11): 401-5.

7. Karki OB, Kunwar D, De A. Benign Breast Diseases: Profile at a Teaching Hospital. American Journal of Public Health Research 2015; 3 (4A): 83-6.

8. Lakshmi SIV, Madhupaka M. Clinicopathological study and management of benign breast disease. PARIPEX - Indian Journal of Research 2017; 6(4): 37-40.

9. Kumar M, Ray K, Harode S, Wagh DD. The Pattern of Benign Breast Diseases in Rural Hospital in India. East and Central African Journal of Surgery2010; 15(2): 59-64.

Source of Support: Nil, Conflict of Interest: None declared.

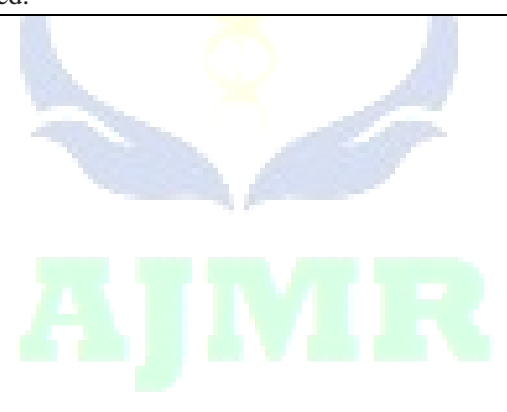

